\title{
Clinical Outcomes of Ileostomy Closure According to Timing During Adjuvant Chemotherapy After Rectal Cancer Surgery
}

\author{
Yoo Jin Choi, Jung-Myun Kwak, Neul Ha, Tae Hoon Lee, Se Jin Baek, Jin Kim, Seon Hahn Kim \\ Division of Colorectal Surgery, Department of Surgery, Korea University Anam Hospital, Korea University College of Medicine, Seoul, Korea
}

Purpose: No guidelines exist detailing when to implement a temporary ileostomy closure in the setting of adjuvant chemotherapy following sphincter-saving surgery for rectal cancer. The aim of this study was to evaluate the clinical and oncological outcomes of ileostomy closure during adjuvant chemotherapy in patients with curative resection of rectal cancer. Methods: This retrospective study investigated 220 patients with rectal cancer undergoing sphincter-saving surgery with protective loop ileostomy from January 2007 to August 2016. Patients were divided into 2 groups: group $1(\mathrm{n}=161)$ who underwent stoma closure during adjuvant chemotherapy and group $2(\mathrm{n}=59)$ who underwent stoma closure after adjuvant chemotherapy.

Results: No significant differences were observed in operative time, blood loss, postoperative hospital stay, or postoperative complications in ileostomy closure between the 2 groups. No difference in overall survival $(\mathrm{P}=0.959)$ or disease-free survival $(\mathrm{P}=0.114)$ was observed between the 2 groups.

Conclusion: Ileostomy closure during adjuvant chemotherapy was clinically safe, and interruption of chemotherapy due to ileostomy closure did not change oncologic outcomes.

Keywords: Rectal neoplasms; Ileostomy; Adjuvant chemotherapy

\section{INTRODUCTION}

A protective loop ileostomy is a temporary stoma made during a sphincter-preserving surgery for rectal cancer. It is often created to divert the fecal stream in order to protect the anastomosis and minimize the rate of anastomotic leakage, which has been shown in several randomized controlled trials $[1,2]$. Recently, 2 metaanalyses demonstrated that the creation of a protective loop ileostomy reduced the leakage rates and number of reoperations, thus ameliorating the severity of anastomotic leakage $[2,3]$.

Received: September 6, 2018 - Accepted: October 18, 2018

Correspondence to: Jung-Myun Kwak, M.D.

Division of Colorectal Surgery, Department of Surgery, Korea University

Anam Hospital, Korea University College of Medicine, 73 Inchon-ro,

Seongbuk-gu, Seoul 02841, Korea

Tel: +82-2-920-5323, Fax: +82-2-928-1631, E-mail: jmkwak@korea.ac.kr ORCID code: https://orcid.org/0000-0002-2181-4279

(C) 2019 The Korean Society of Coloproctology

This is an open-access article distributed under the terms of the Creative Commons Attribution NonCommercial License (http://creativecommons.org/licenses/by-nc/4.0) which permits unrestricted noncommercial use, distribution, and reproduction in any medium, provided the original work is properly cited.
However, stoma-related complications are considerable and include dehydration caused by high output, electrolyte imbalance, peristomal dermatitis, parastomal hernia, and bowel obstruction $[4,5]$. A patient's overall quality of life (QoL) is compromised by stoma-related problems, such as frequent bag leakage and loss of privacy when emptying bags $[4,5]$. Psychological problems also affect QoL, and patients report low sexuality and body image concerns stemming from difficulty wearing clothing and feeling unattractive $[6,7]$.

Therefore, an ileostomy should be reversed as early as possible to reduce stoma-related complications and improve patients' QoL. However, there is no optimal time to reverse a temporary ileostomy. Several studies have reported the safety and feasibility of early stoma closure (within 2 weeks after initial surgery) with promising results [8-10]. On the other hand, other studies showed that complications were significantly associated with a shorter interval between primary operation and ileostomy closure [11, 12]. Generally, the available literature is scarce about the optimal timing for reversal of protective loop ileostomy, and it is typically reversed 8-12 weeks after rectal cancer surgery [8]. 
During this interval period, some patients are receiving adjuvant chemotherapy, which usually lasts 4 to 6 months after surgery. Some studies suggest avoiding closure surgery during adjuvant chemotherapy $[13,14]$ because ileostomy closure during adjuvant chemotherapy can be dangerous for the following potentially valid reasons. First, there is concern whether chemotherapy disturbs proper wound healing of the ileostomy closure. Second, interruption or delay of chemotherapy due to ileostomy closure may alter chemotherapy's effects and lead to inferior survival [1517]. Additionally, if serious complications occur, the delay of adjuvant chemotherapy could be prolonged and the negative effects on survival and patient QoL intensified $[18,19]$.

Our colorectal department schedules ileostomy closure within three months after the initial surgery, regardless of adjuvant chemotherapy, if there is no more risk of anastomotic complication. Very few studies have been published about the feasibility of ileostomy closure during adjuvant chemotherapy $[20,21]$. The aim of this study was to evaluate the clinical and oncological outcomes of ileostomy closure during adjuvant chemotherapy after curative resection of rectal cancer.

\section{METHODS}

Data was retrospectively extracted from a prospectively collected colorectal cancer database. This study was approved by the Institutional Review Board of Korea University Anam Hospital (approval number: 2018AN03000) and was eligible for exemption from informed consent.

\section{Patients}

Patients who were diagnosed with rectal adenocarcinoma and underwent sphincter-preserving surgery with total/partial mesorectal excision and temporary loop ileostomy for curative intent and received adjuvant chemotherapy at Korea University Anam Hospital (Seoul, Korea) between January 2007 and August 2016 were included.

Exclusion criteria were stage IV rectal cancers, ileostomy creation for management of leakage or any other complication of anastomosis after the initial surgery, and reoperation after the initial surgery. Patients who received radiotherapy postoperatively were also excluded.

Patients were divided into 2 groups according to timing of stoma closure: group 1 who underwent ileostomy closure during chemotherapy and group 2 who underwent ileostomy closure after completion of chemotherapy. Data from the 2 groups were compared for patient demographics, tumor characteristics, pathologic results, and operative and postoperative outcomes including survival.

\section{Stoma closure scheduling}

The timing of stoma closure was predominantly decided by the surgeon's preference and the patient's needs. Before closure, the anastomosis was evaluated with sigmoidoscopy and lower gastrointestinal (GI) series to confirm the absence of leakage, sinus, fistula, or any other problems. Lower GI series X-rays displayed the anastomotic sites after Gastrografin insertion into the rectum by a rectal tube.

If stoma closure was scheduled during adjuvant chemotherapy, surgery was considered after 3-4 cycles of chemotherapy and prepared in a routine manner. Patients for whom there was no suspicion of anastomotic problems underwent ileostomy closure 2 weeks after the last administration of chemotherapy. If they had no stoma closure complications, the next chemotherapy was given approximately 2 weeks after discharge.

\section{Outcome measures}

Rectal cancer was defined as pathologically-demonstrated adenocarcinoma located in the rectum, $15 \mathrm{~cm}$ or less from the anal verge on the rigid sigmoidoscope. The low rectum was defined as 2 to $7 \mathrm{~cm}$ from the anal verge, the mid rectum as 8 to $12 \mathrm{~cm}$ from the anal verge, and the upper rectum as 13 to $15 \mathrm{~cm}$ from the anal verge.

Postoperative complications after stoma closure and overall survival (OS)/disease-free survival (DFS) were analyzed to evaluate the feasibility of stoma closure during adjuvant chemotherapy. Other parameters, such as operative time, postoperative hospital stay, readmission, reoperation, and mortality related to ileostomy closure were also analyzed.

Postoperative complications after ileostomy closure were defined as any surgical or medical complications that developed within 30 days after stoma closure. OS was defined as the interval between the initial rectal cancer surgery and the last day of hospital follow-up in any department or death, if known. DFS was defined as the date of the first recurrence or the last day of follow-up examination related to rectal cancer.

\section{Statistical analysis}

Categorical variables are reported as numbers with percentages and were analyzed using the chi-square test or Fisher exact test. Continuous variables are described as mean and standard deviation and analyzed using the Mann-Whitney U-test. Survival analyses were performed by the Kaplan-Meier method. Differences between survival curves were analyzed by the log-rank test. Statistical analysis was performed using IBM SPSS Statistics ver. 22.0 (IBM Co., Armonk, NY, USA), and P-values less than 0.05 were considered statistically significant.

\section{RESULTS}

A total of 220 patients were selected for this study and divided into 2 groups: group 1 was composed of patients who received stoma closure during chemotherapy and group 2 was composed of patients who received stoma closure after chemotherapy. Group 1 comprised 161 patients and group 2 comprised 59 pa- 


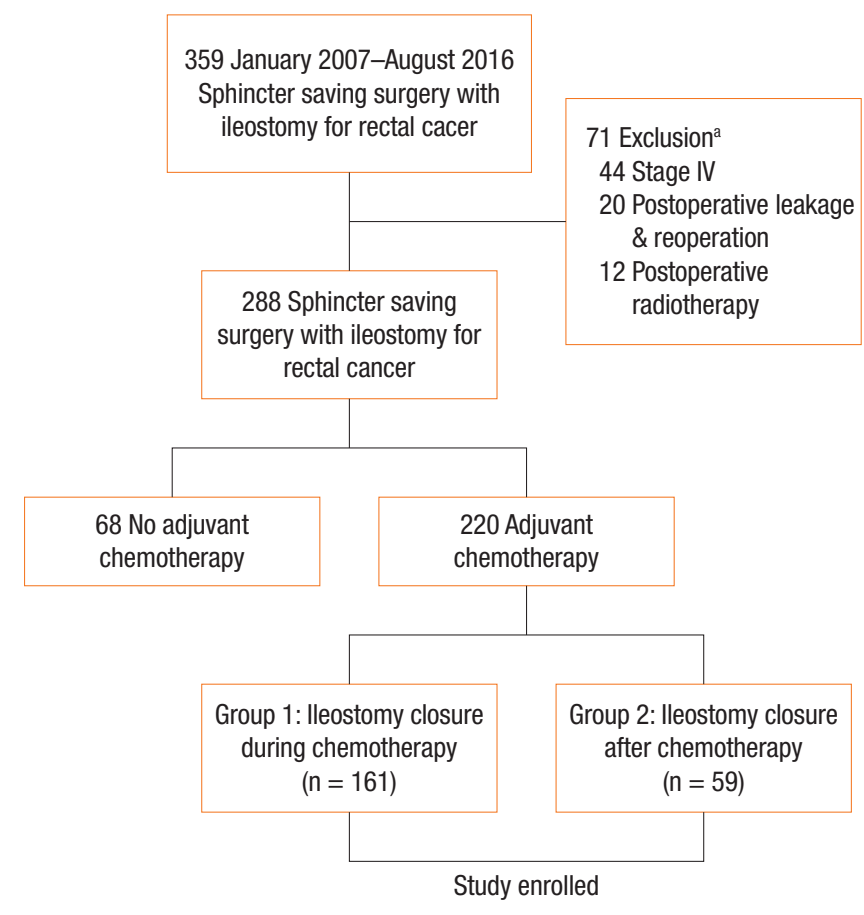

Fig. 1. Case selection diagram showing inclusion and exclusion crite-

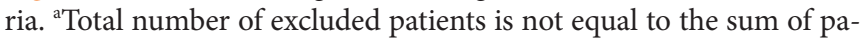
tients for each exclusion criterion.

tients (Fig. 1). No differences were observed between the two groups in gender ratio, body mass index (BMI), preoperative chemoradiation, type of surgery, and surgical procedure (Table 1). Tumors located in the low rectum were more common in group 2. Although clinical TNM stage based on preoperative computed tomography and magnetic resonance imaging was not different, more advanced pathologic stage was observed in group 2 , and the adjuvant chemotherapy regimen was different between the 2 groups.

No significant differences were observed in operative time, estimated blood loss, interval for resuming diet, or postoperative hospital stay (Table 2). Overall, 30-day postoperative complications were $8.7 \%$ in group 1 and $15.3 \%$ in group 2, which was not statistically different. Two patients from group 1 underwent reoperation; one patient had a re-ileostomy for rectovaginal fistula, and another had a bleeding control reoperation for hematochezia. Three patients from group 2 underwent reoperation; one patient had perianal abscess drainage and re-ileostomy for severe diarrhea, another had rectal strictureplasty for anastomosis stricture, and the third patient had re-ileostomy for rectourethral fistula. Two patients in group 1 and 5 patients in group 2 required readmission. Most readmissions were for postoperative ileus. No mortality after ileostomy closure was observed in the 2 groups.

The mean follow-up period was $53.7 \pm 28.1$ months in group 1 and $62.2 \pm 31.2$ months in group 2 . No differences were observed in OS and DFS between groups 1 and $2(\mathrm{P}=0.959$ for OS, $\mathrm{P}=$
Table 1. Patient characteristics and demographics

\begin{tabular}{|c|c|c|c|}
\hline Parameter & $\begin{array}{l}\text { Group 1 } \\
(n=161)\end{array}$ & $\begin{array}{l}\text { Group } 2 \\
(\mathrm{n}=59)\end{array}$ & P-value \\
\hline Age (yr) & $59.4 \pm 12.3$ & $58.1 \pm 10.7$ & 0.474 \\
\hline Sex & & & 0.666 \\
\hline Male & $121(75.2)$ & $46(78.0)$ & \\
\hline Female & $40(24.8)$ & $13(22.0)$ & \\
\hline ASA PS classification & & & 0.285 \\
\hline I & 55 (34.2) & $27(45.8)$ & \\
\hline$\|$ & $102(63.4)$ & $31(52.5)$ & \\
\hline III & $4(2.5)$ & $1(1.7)$ & \\
\hline Body mass index $\left(\mathrm{kg} / \mathrm{m}^{2}\right)$ & $23.3 \pm 3.2$ & $23.3 \pm 2.9$ & 0.948 \\
\hline Tumor location & & & 0.035 \\
\hline Upper rectum & $10(6.2)$ & $0(0)$ & \\
\hline Mid rectum & $54(33.5)$ & $14(23.7)$ & \\
\hline Lower rectum & $97(60.2)$ & 45 (76.3) & \\
\hline Tumor height from anal verge $(\mathrm{cm})$ & $6.2 \pm 2.9$ & $5.2 \pm 2.3$ & 0.019 \\
\hline Preoperative chemoradiation & & & 0.367 \\
\hline Yes & $79(49.1)$ & $33(55.9)$ & \\
\hline No & $82(50.9)$ & $26(44.1)$ & \\
\hline Type of surgery & & & 0.425 \\
\hline Laparoscopic & $71(44.1)$ & $21(35.6)$ & \\
\hline Robotic & 89 (55.3) & $37(62.7)$ & \\
\hline Conversion to open & $1(0.6)$ & $1(1.7)$ & \\
\hline Surgical procedure & & & 0.520 \\
\hline High anterior resection & $2(1.2)$ & $0(0)$ & \\
\hline Low anterior resection & $123(76.4)$ & $41(69.5)$ & \\
\hline Intersphincteric resection & $36(22.4)$ & $18(30.5)$ & \\
\hline cTNM stage & & & 0.948 \\
\hline I & $8(5.0)$ & $3(5.1)$ & \\
\hline$\|$ & $16(9.9)$ & $5(8.5)$ & \\
\hline III & $137(85.1)$ & $51(86.4)$ & \\
\hline ypTNM stage & & & 0.049 \\
\hline 0 & $2(1.2)$ & $0(0)$ & \\
\hline I & $7(4.3)$ & $2(3.4)$ & \\
\hline$\|$ & $79(49.1)$ & $18(30.5)$ & \\
\hline III & 73 (45.3) & 39 (66.1) & \\
\hline Adjuvant chemotherapy & & & 0.001 \\
\hline FOLFOX & 75 (46.6) & 43 (72.9) & \\
\hline FOLFIRI & $2(1.2)$ & $0(0)$ & \\
\hline $\mathrm{FL}$ & $29(18.0)$ & $8(13.6)$ & \\
\hline Oral 5-FU & 55 (34.2) & $8(13.6)$ & \\
\hline
\end{tabular}

Values are presented as mean \pm standard deviation or number of patients (\%). Group 1, ileostomy closure during chemotherapy; group 2, ileostomy closure after chemotherapy; ASA PS, American Society of Anesthesiologist physical status; FOLFOX, folinic acid, FU, and oxaliplatin; FOLFIRI, folinic acid, FU, and irinotecan; FL, FU and leucovorin; FU, fluorouracil. 
Table 2. Perioperative outcomes of ileostomy closure

\begin{tabular}{|c|c|c|c|}
\hline Parameter & $\begin{array}{l}\text { Group } 1 \\
(n=161)\end{array}$ & $\begin{array}{l}\text { Group } 2 \\
(n=59)\end{array}$ & P-value \\
\hline Interval to ileostomy closure (day) & & & $<0.001$ \\
\hline Mean $\pm S D$ & $88.0 \pm 27.6$ & $201.8 \pm 112.3$ & \\
\hline Median (range) & $86.3(14-173)$ & $172.3(91-813)$ & \\
\hline Operative time (min) & $77.8 \pm 106.3$ & $96.3 \pm 30.4$ & 0.188 \\
\hline Estimated blood loss (mL) & $11.2 \pm 83.7$ & $5.1 \pm 39.1$ & 0.591 \\
\hline Interval for resuming diet (day) & $2.5 \pm 1.2$ & $3.2 \pm 3.5$ & 0.032 \\
\hline Postoperative hospital stay (day) & $5.8 \pm 3.3$ & $8.0 \pm 12.9$ & 0.048 \\
\hline $\begin{array}{l}30 \text { - Day postoperative } \\
\text { complication }^{\mathrm{a}}\end{array}$ & $14(8.7)$ & $9(15.3)$ & 0.159 \\
\hline Superficial SSI & 1 & 2 & \\
\hline Deep SSI & 0 & 2 & \\
\hline Leakage & 0 & 0 & \\
\hline Bleeding & 1 & 0 & \\
\hline lleus & 10 & 8 & \\
\hline Deep vein thrombosis & 0 & 1 & \\
\hline Cerebrovascular infarction & 1 & 0 & \\
\hline Postoperative urinary retention & 1 & 1 & \\
\hline Wound hematoma & 1 & 0 & \\
\hline $\begin{array}{l}\text { Long-term anastomotic } \\
\text { complication }\end{array}$ & $1(0.6)$ & $2(3.4)$ & $0.176^{b}$ \\
\hline Anastomotic stricture & 0 & 1 & \\
\hline Rectourethral fistula & 0 & 1 & \\
\hline Rectovaginal fistula & 1 & 0 & \\
\hline Reoperation & $2(1.2)$ & $3(5.1)$ & $0.121^{b}$ \\
\hline Readmission & $2(1.2)$ & $5(8.5)$ & $0.016^{b}$ \\
\hline Mortality & 0 & 0 & NA \\
\hline
\end{tabular}

Values are mean \pm standard deviation (SD) or number (\%) unless otherwise indicated.

Group 1, ileostomy closure during chemotherapy; group 2, ileostomy closure after chemotherapy; SSI, surgical site infection; NA, not available.

aThe total number of patients who had postoperative complications is not equal to the sum of patients for each complication. ${ }^{b}$ Fisher exact test.

0.114 for DFS). In a subgroup analysis according to the pathologic stage, there were no differences in OS and DFS in patients with ypStage II and ypStage III rectal cancers (Fig. 2).

\section{DISCUSSION}

This study compared the clinical and oncological outcomes between patients who underwent closure of a temporary ileostomy either during adjuvant chemotherapy or after chemotherapy. This study showed that there were no significant differences between the two groups in postoperative hospital stay, complications, and mortality. These results illustrated that ileostomy closure during chemotherapy was safe, and chemotherapy did not affect the surgical outcome of ileostomy closure. These findings suggest that stoma closure during chemotherapy can achieve a clinical safety level equal to stoma closure after chemotherapy. Therefore, closing a stoma during adjuvant chemotherapy seems to be safe and feasible. This result agrees with findings from previous studies [20,21].

Temporary loop ileostomy is an indispensable choice for fecal diversion in order to protect an anastomosis and minimize the clinical significance of anastomotic leakage. However, an ileostomy frequently causes serious morbidity, decreases patient QoL, and may cause irreversible damage [7]. When considering patient QoL and morbidity, closing an ileostomy as early as possible is crucial, and early closure has been studied rigorously over the last decade $[11,12,22]$.

However, adjuvant chemotherapy, which usually lasts 4 to 6 months after surgery in patients with advanced stage disease, must be considered. Although no confirmed guidelines have been suggested, the consensus is that ileostomy closure should be postponed until completion of adjuvant chemotherapy because some surgeons believe that chemotherapy may interrupt wound healing following ileostomy closure [13, 14]. Also, if ileostomy closure is performed during chemotherapy, the chemotherapy schedule should be interrupted. Possible serious postoperative complications may extensively delay chemotherapy resumption and thus reduce disease-free survival. For example, in our center, patients who underwent an uneventful ileostomy closure usually started their next chemotherapy about 4 weeks after the previous chemotherapy. As a result, chemotherapy was one cycle off for those patients, depending on their schedule. In Western countries, ileostomy closure is often further complicated in obese patients who may have more severe postoperative complications that extensively delay chemotherapy. Therefore, the feasibility of ileostomy closure during chemotherapy can be rationalized after clinical safety and oncological outcomes have been discussed among clinicians supported by evidence.

In one of the first studies on the timing of ileostomy closure, Tulchinsky et al. [20] reported that closure during chemotherapy did not worsen short-term outcomes, such as length of hospital stay, rate of ileostomy closure complications, and mortality. This result correlates with our study result of no significant differences in those 3 parameters between the 2 groups. They also provided evidence countering the assumption that ileostomy closure during chemotherapy might interrupt adjuvant treatment and influence disease recurrence. Their P-values for OS and for recurrence free survival were 0.35 and 0.95 , respectively, agreeing with the rates reported in our study $(\mathrm{P}=0.959, \mathrm{P}=0.114$, respectively) which showed that delayed chemotherapy did not affect oncological outcomes.

However, the optimal timing of stoma closure in the setting of adjuvant chemotherapy remains controversial [8-12]. No randomized studies investigating the influence of chemotherapy interruption on oncologic outcomes have been published. Since ad- 

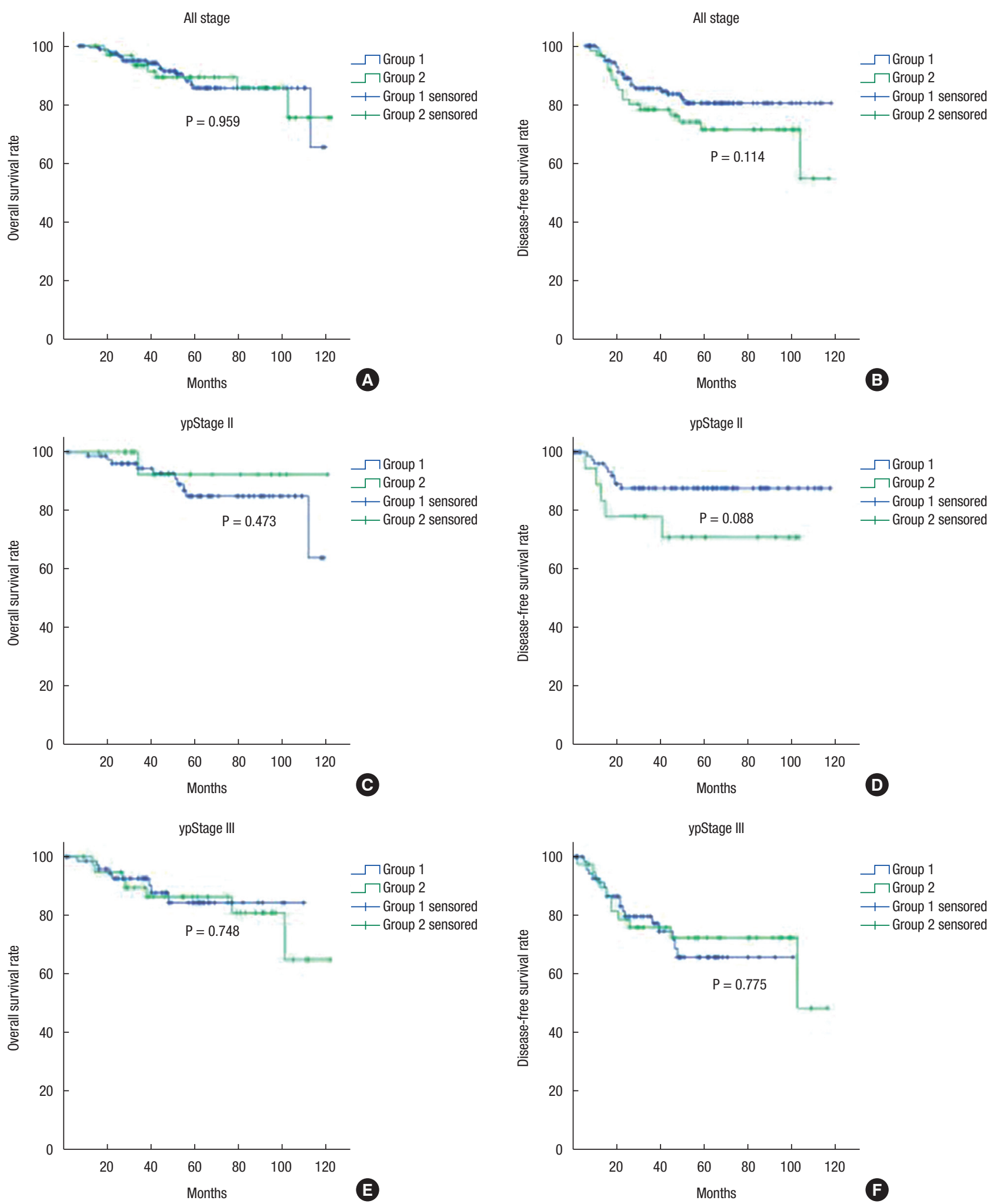

Fig. 2. Survival analysis between the 2 groups: (A) overall survival in all patients, (B) disease-free survival in all patients, (C) overall survival in patients with ypStage II, (D) disease-free survival in patients with ypStage II, (E) overall survival in patients with ypStage III, and (F) disease-free survival in patients with ypStage III. 
juvant chemotherapy (including oxaliplatin) is considered to improve long-term survival in advanced rectal cancer $[23,24]$, serious complications after stoma closure can impair the completion of chemotherapy and lead to inferior survival. Further investigation is warranted.

The current study was limited by its retrospective nature with selection bias. Certain factors affected the patient's and surgeon's decision regarding the timing of ileostomy closure, and some patients chose to have their ileostomy closed during chemotherapy and others chose closure after chemotherapy. Two factors might explain this decision: surgeon preference and patient status. Most surgeons in this study routinely close an ileostomy during chemotherapy, although some surgeons prefer to perform ileostomy closure only after completion of chemotherapy. Regarding patient status, closure schedules were usually postponed until after chemotherapy for patients with anastomosis problems, such as pelvic abscess, anastomotic sinus, or fistula. In addition, a patient's desire to close a stoma might affect the surgeon's decision. Different types of chemotherapy recommended by different guidelines and insurance policies throughout the 10 years of this study are other limitations. Nevertheless, our study has strong advantages because there is only a very small amount of previous literature available on this subject. The total number of patients in this study $(n=220)$ was enough to have statistical power.

In conclusion, this report suggests that ileostomy closure during chemotherapy seems clinically safe and without negative effect on oncologic outcomes, possibly providing new insights into the feasibility of protective ileostomy closure during adjuvant chemotherapy. A well-planned prospective study to investigate how early stoma closure during chemotherapy positively affects patient QoL would be worthwhile.

\section{CONFLICT OF INTEREST}

No potential conflict of interest relevant to this article was reported.

\section{REFERENCES}

1. Matthiessen P, Hallbook O, Rutegard J, Simert G, Sjodahl R. Defunctioning stoma reduces symptomatic anastomotic leakage after low anterior resection of the rectum for cancer: a randomized multicenter trial. Ann Surg 2007;246:207-14.

2. Hüser N, Michalski CW, Erkan M, Schuster T, Rosenberg R, Kleeff J, et al. Systematic review and meta-analysis of the role of defunctioning stoma in low rectal cancer surgery. Ann Surg 2008; 248:52-60.

3. Tan WS, Tang CL, Shi L, Eu KW. Meta-analysis of defunctioning stomas in low anterior resection for rectal cancer. Br J Surg 2009; 96:462-72.

4. Giannakopoulos GF, Veenhof AA, van der Peet DL, Sietses C, Meijerink WJ, Cuesta MA. Morbidity and complications of pro- tective loop ileostomy. Colorectal Dis 2009;11:609-12.

5. Akesson O, Syk I, Lindmark G, Buchwald P. Morbidity related to defunctioning loop ileostomy in low anterior resection. Int J Colorectal Dis 2012;27:1619-23.

6. Neuman HB, Patil S, Fuzesi S, Wong WD, Weiser MR, Guillem JG, et al. Impact of a temporary stoma on the quality of life of rectal cancer patients undergoing treatment. Ann Surg Oncol 2011; 18:1397-403.

7. Neuman HB, Park J, Fuzesi S, Temple LK. Rectal cancer patients' quality of life with a temporary stoma: shifting perspectives. Dis Colon Rectum 2012;55:1117-24.

8. Alves A, Panis Y, Lelong B, Dousset B, Benoist S, Vicaut E. Randomized clinical trial of early versus delayed temporary stoma closure after proctectomy. Br J Surg 2008;95:693-8.

9. Lasithiotakis K, Aghahoseini A, Alexander D. Is early reversal of defunctioning ileostomy a shorter, easier and less expensive operation? World J Surg 2016;40:1737-40.

10. Danielsen AK, Park J, Jansen JE, Bock D, Skullman S, Wedin A, et al. Early closure of a temporary ileostomy in patients with rectal cancer: a multicenter randomized controlled trial. Ann Surg 2017;265:284-90.

11. Bakx R, Busch OR, van Geldere D, Bemelman WA, Slors JF, van Lanschot JJ. Feasibility of early closure of loop ileostomies: a pilot study. Dis Colon Rectum 2003;46:1680-4.

12. Perez RO, Habr-Gama A, Seid VE, Proscurshim I, Sousa AH Jr, Kiss DR, et al. Loop ileostomy morbidity: timing of closure matters. Dis Colon Rectum 2006;49:1539-45.

13. Robertson I, Leung E, Hughes D, Spiers M, Donnelly L, Mackenzie I, et al. Prospective analysis of stoma-related complications. Colorectal Dis 2005;7:279-85.

14. Biagi JJ, Raphael MJ, Mackillop WJ, Kong W, King WD, Booth $\mathrm{CM}$. Association between time to initiation of adjuvant chemotherapy and survival in colorectal cancer: a systematic review and meta-analysis. JAMA 2011;305:2335-42.

15. Des Guetz G, Nicolas P, Perret GY, Morere JF, Uzzan B. Does delaying adjuvant chemotherapy after curative surgery for colorectal cancer impair survival? A meta-analysis. Eur J Cancer 2010;46: 1049-55.

16. Bayraktar UD, Chen E, Bayraktar S, Sands LR, Marchetti F, Montero AJ, et al. Does delay of adjuvant chemotherapy impact survival in patients with resected stage II and III colon adenocarcinoma? Cancer 2011;117:2364-70.

17. Hershman D, Hall MJ, Wang X, Jacobson JS, McBride R, Grann VR, et al. Timing of adjuvant chemotherapy initiation after surgery for stage III colon cancer. Cancer 2006;107:2581-8.

18. Thalheimer A, Bueter M, Kortuem M, Thiede A, Meyer D. Morbidity of temporary loop ileostomy in patients with colorectal cancer. Dis Colon Rectum 2006;49:1011-7.

19. Sharma A, Deeb AP, Rickles AS, Iannuzzi JC, Monson JR, Fleming FJ. Closure of defunctioning loop ileostomy is associated with considerable morbidity. Colorectal Dis 2013;15:458-62.

20. Tulchinsky H, Shacham-Shmueli E, Klausner JM, Inbar M, Geva 
R. Should a loop ileostomy closure in rectal cancer patients be done during or after adjuvant chemotherapy? J Surg Oncol 2014; 109:266-9.

21. Figueiredo MN, Mege D, Maggiori L, Ferron M, Panis Y. When is the best time for temporary stoma closure in laparoscopic sphincter-saving surgery for rectal cancer? A study of 259 consecutive patients. Tech Coloproctol 2015;19:469-74.

22. Zhou MW, Wang ZH, Chen ZY, Xiang JB, Gu XD. Advantages of early preventive ileostomy closure after total mesorectal excision surgery for rectal cancer: an institutional retrospective study of 123 consecutive patients. Dig Surg 2017;34:305-11.

23. Rodel C, Graeven U, Fietkau R, Hohenberger W, Hothorn T, Ar- nold D, et al. Oxaliplatin added to fluorouracil-based preoperative chemoradiotherapy and postoperative chemotherapy of locally advanced rectal cancer (the German CAO/ARO/AIO-04 study): final results of the multicentre, open-label, randomised, phase 3 trial. Lancet Oncol 2015;16:979-89.

24. Hong YS, Nam BH, Kim KP, Kim JE, Park SJ, Park YS, et al. Oxaliplatin, fluorouracil, and leucovorin versus fluorouracil and leucovorin as adjuvant chemotherapy for locally advanced rectal cancer after preoperative chemoradiotherapy (ADORE): an open-label, multicentre, phase 2, randomised controlled trial. Lancet Oncol 2014;15:1245-53. 